\title{
Argumentation and the Force of Reasons
}

\author{
RoBert C. PINTO \\ Centre for Research in Reasoning, Argumentation and Rhetoric \\ Department of Philosophy \\ University of Windsor \\ Windsor, ON \\ Canada N9B 3P4 \\ pinto@uwindsor.ca \\ pinto.robert@gmail.com
}

\begin{abstract}
Argumentation involves offering and/or exchanging reasons - either reasons for adopting various attitudes towards specific propositional contents or else reasons for acting in various ways. This paper develops the idea that the force of reasons is through and through a normative force because what good reasons accomplish is precisely to give one a certain sort of entitlement to do what they are reasons for. The paper attempts to shed light on what it is to have a reason, how the sort of entitlement arising from reasons differs from other species of entitlement and how the norms by which such entitlement is assessed obtain their status as norms.
\end{abstract}

Résumé: L'argumentation entraîne un échange et/ou une proposition de raisons dans le but de convaincre quelqu'un d'adop-ter soit diverses attitudes envers des contenus spécifiques propo-sitionnels ou soit diverses actions. Dans cet article on donne des précisions sur l'idée que la force des raisons est de bout en bout une force normative parce que des bonnes raisons nous donnent une sorte de droit à faire ce qu'elles appuient. One essaie de mettre en lumière en quoi consiste avoir une raison, comment ce droit proven-ant des raisons diffère des autres espèces de droits, et comment les normes par l'entremise desquels on évalue ce droit obtiennent le statut de droit

Keywords: cognitive attitudes, conative attitudes, defeasibility, dialectic, evaluative attitudes, forces of reasons, justification, logic, norms, perspectives on argumentation, reasonable, reasons, rhetoric

\section{Introduction}

The theme of the 2009 OSSA conference is Argument Cultures something which may be taken to mean the various cultures of theorizing about arguments and argumentation. With respect to these varying cultures, Tindale (1999, pp. 3-4) has identified three "perspectives" on what argument or arguing entails - the logical, the dialectical and the rhetorical. Of course, within each of these 
there are a variety of ways in which the perspectives can unfold or develop. Formal and informal logic represent quite different species of "logical" perspective on argument, and themselves divide into varieties of sub-species. The formal dialectic of Hamblin (1970, esp. chapter 8) or of Barth and Krabbe (1982), the "controversy-oriented approach to the theory of knowledge" in Rescher (1977), the pragmatic-dialectic approach of the Amsterdam school, and the somewhat different dialogue approach that Walton takes (see for instance Walton and Krabbe 1995) are among the quite different species of dialectical approach. And finally you will find just some of often quite different approaches that may be classed as rhetorical in Aristotle, Cicero, Perelman, Wenzel, Tindale himself, as well as in the design theoretic approach to normative pragmatics inspired by the work of Scott Jacobs and Fred Kauffeld and described by Goodwin (2002).

However, across this broad spectrum of "cultures of theorizing" there appears to be general agreement that arguing involves offering and/or exchanging reasons. My aim in what follows is to outline a general account of reasons - of what it is to have them and of what is required to offer or present them. My intent is to outline a way of thinking about reasons that is neutral with respect to the "perspectives" on argumentation and the "cultures' associated with them, but which can, perhaps, throw at least some light on why there can be such different approaches to practices which turn on the presentation and exchanging of reasons.

Philosophical discussions of reasons have tended to focus either on reasons for action or on reasons for belief. But it is a mistake to limit our purview to one or another of these two, or only to these two. To start with, there are reasons for cognitive attitudes other than belief - reasons for doubting, reasons for expecting that something will turn out to be the case, reasons for presuming, and so on. Moreover, there are reasons for adopting or holding conscious attitudes other than cognitive attitudes - for example, reasons for wanting this or that to be the case, reasons for choosing one or another course of action (i.e. forming an intention to engage in that course of action), reasons for fearing, reasons for hoping, reasons for preferring one thing over another, and so on.

One way to capture the broad array of reasons that we need to take account of is to say that we are (or ought to be) concerned with reasons for doing, where 'doing' is used in the very broadest of senses and is not limited to "actions" that are overt and/or deliberate - a sense of 'doing' in which it applies not only to actions, but to holding almost any sort of conscious attitude as well. In what follows, my discussion will highlight conscious 
propositional attitudes, both as states that can provide us with reasons for doing things, as well as states for which there can be reasons. ${ }^{1}$

I should add that the account which follows recognizes three principal categories of conscious propositional attitude - cognitive, conative and evaluative. This classification reflects Rescher's recognition (Rescher 1988, p. 3ff.) of three types of rationality: cognitive rationality (whose "product" is factual contentions or beliefs), practical rationality (whose "product" is action recommendations or injunctions), and evaluative rationality (whose product is evaluation or appraisal). ${ }^{2}$

Let me mention two advantages of broadening our account of reasons along the lines I propose.

(a) Since one species of cognitive attitude consists of a range of doxastic or belief-like attitudes - suspecting that something is the case, being inclined to believe it, expecting it will turn out to be the case, presuming it to be the case, as well as straightforwardly or fully believing it to be the case - this proposal opens up the possibility of adopting a qualitative version of evidence proportionalism, ${ }^{3}$ a view according to

\footnotetext{
${ }^{1}$ In my view, there are in fact conscious attitudes other than propositional attitudes for which we can have reasons - reasons for liking someone, reasons for distrusting someone, and so on - see Pinto 2001, chapter 2 ("Generalizing the notion of argument"), esp. pp. 17-19. For purposes of this paper I will simply ignore conscious attitudes toward non-propositional objects and the reasons we may have for adopting them.

${ }^{2}$ Davidson (1963/2001) offers an account of the primary reason of an action as consisting of a belief and a pro-attitude. Some instances of 'pro-attitudes' would fall under my category of conative attitudes, others would fall under my category of evaluative attitudes. One reason I find it useful to distinguish between these two sorts of pro-attitude is the fact that I think that typically our reasons for adopting conative attitudes - commitments to bring about certain goals or intentions to act in a certain way - lie in evaluative attitudes. For example, among my reasons for deciding (i.e. forming the intention) to go for a swim today will be the fact that that I value physical exercise and that I prefer swimming to most other sorts of physical exercise.

${ }^{3}$ Feldman and Conee (1985, p. 15) appear to advance a qualitative version of evidence proportionalism in their formulation of the principle they call EJ: "Doxastic attitude D toward proposition $\mathrm{p}$ is epistemically justified for $\mathrm{S}$ at $\mathrm{t}$ if and only if having D toward $p$ fits the evidence $S$ has at t." However, the only doxastic attitudes they explicitly mention are belief, suspension of belief and disbelief. In note 1, they say "EJ is compatible with the existence of varying strengths of belief and disbelief. If there is such variation, then the greater the preponderance of evidence, the stronger the doxastic attitude that fits the evidence." Recognizing varying "degrees of belief" need not commit one to a quantitative version of proportionalism - everything depends on how the "varying strengths" are characterized. Counterparts of the three doxastic attitudes
} 
which the type of doxastic attitude we adopt must be appropriate in the light of the reasons available to us - a variety of evidence proportionalism that has no need to quantify degrees of belief or to quantify degrees of support. ${ }^{4}$

(b) The proposal enables us to unpack the idea of being or having a reason in such a way that we can say, along with Rescher (1988, p. 4)

Rationality... pivots on the deployment of 'good reasons': I am being rational if my doings are governed by suitably good reasons - if I proceed in cognitive, practical and evaluative contexts on the basis of cogent reasons for what I do.

The approach to reasons outlined here provides a way of extending the reach of reasons to the broad range of contexts that Rescher has in mind and gives us a way of formulating questions about the interplay among reasons operative in these different contexts.

\section{The force of reasons as a normative force}

Let me begin by recalling what Davidson and Dennettt said quite some time ago about explaining an action by citing an agent's reasons for taking that action.

Davidson (1962/2001, p. 3) calls explanations in terms of reasons "rationalizations," and says that a reason

rationalizes an action only if it leads us to see something the agent saw, or thought he saw, in his action - some feature, consequence, or aspect of the action the agent wanted, desired, prized, held dear, thought dutiful, beneficial, obligatory or agreeable.

explicitly mentioned by Feldman and Conee can also be found in the three types of "standpoint" that may be taken toward a "view" that are recognized by van Emeren and Grootendorst (1992, pp. 15-16).

${ }^{4}$ Though there are obvious ways to quantify (assign a real or cardinal number to) the degree of support that a reason affords its conclusion for some types of reasons (e.g.., those reasons which exhibit the pattern which Pollock (1995) calls "statistical syllogism"), how to extend quantification of degree of support to many other types of reason is not obvious. One way of doing so is proposed by Pollock (1995, p. 93-94) - it involves the supposition that we can in effect intuitively (my word, not Pollock's) equate the degree of support offered by any sort of argument with the degree of support offered by a related argument having the form of statistical syllogism (I omit the details). Pollock himself notes (p. 94) that there are possible objections to the universal application of this strategy. I myself am inclined to think that any method of assigning a number to the support that "He promised to do X" gives to "He ought to do X" will produce results that are quite artificial. 


\section{Robert Pinto}

He goes on to say his account of the primary reasons for an action requires that "that the agent have certain beliefs and attitudes in the light of which the action is reasonable" (p. 9, italics mine). ${ }^{5}$

Dennettt (1978, p 236) calls explanations in terms of reasons "intentional explanations" and says that they

explain by giving a rationale for the explicandum. Intentional explanations explain a bit of behavior, an action, or a stretch of inaction, by making it reasonable in the light of certain beliefs, intentions, desires ascribed to the agent.

Dennettt (1978, p. 388) explicitly identifies reasons for action with the beliefs, desires, etc., in light of which actions become reasonable:

We typically render actions intelligible by citing their reasons, the beliefs and desires of the agent that render the actions at least marginally reasonable under the circumstances.

In these passages Davidson and Dennettt are talking about reasons for action, not reasons for belief. But I submit that the common element in what Davidson and Dennett say about reasons for action also applies to a person's reasons for believing or accepting a proposition. For example, if I say

Sarah believes that that her father won't go to work tomorrow because she thinks tomorrow is a holiday

I explain Sarah's belief by "giving a rationale", that is by making the belief to be explained appear reasonable by citing another belief

\footnotetext{
${ }^{5}$ It is perhaps worth noting that when "Actions, Reasons and Causes" was reprinted in Davidson 2001, Davidson wrote (p. xvi):

"Actions, Reasons, and Causes" was a reaction against a widely accepted doctrine that the explanation of an intentional action in terms of its motives or reasons could not relate reasons and actions as cause and effect. A principal argument was that causal relations are essentially nomological and based on induction while our knowledge that an agent has acted on certain reasons is not usually dependent on induction or knowledge of serious laws. The argument had found influential if brief expression in Wittgenstein's Blue and Brown Books, which were widely circulated from the middle thirties onward (though published only in 1958). In Essay 1 I accept the view that teleological explanation of action differs from explanation in the natural sciences in that laws are not essentially involved in the former but hold that both sorts of explanation can, and often must, invoke causal connections.
} 
in light of which the it is reasonable "from the believer's point of view."

In what follows I shall assume, therefore, that reasons for belief, like reasons for action, also explain by "giving a rationale" for the belief to be explained, and therefore explain by making the explicandum reasonable in the light of other things that person believes or accepts.

Now to say that what makes something a reason for an action or belief is the fact that it renders the action or belief reasonable does not look like a very promising strategy. For it is hard to see how we can make sense of something's being reasonable without appealing to a prior notion of reasons for it.

Davidson (1963/2001, p. 9) had observed that the reasons for an action "justify" it." And we might be tempted to make sense of what reasons are by saying that the beliefs, desires, etc., which render doing something (at least provisionally) reasonable do so because they "justify" it. But to proceed in that way is, I think, to get things backwards. The careful examination and criticism of the use of the expression "epistemic justification" recently offered by William Alston (2005, chapter 1) should make it clear that if we want to appeal to a notion of "justification" we must, at the very least, first pin down what we take such justification to consist in.

Robert Brandom (1994, p. 56) takes still another approach when, commenting on "intentional explanations," he observes that "attributing suitably related beliefs and desires is attributing a certain sort of reason for action" but that it "is not yet to say that the one who has such a reason will act according to it...." He says,

\begin{abstract}
What follows immediately from the attribution of intentional states that amount to a reason for action is just that (ceteris paribus) the individual who has that reason ought to act in a certain way. This 'ought' is a rational ought -- someone with those beliefs and
\end{abstract}

\footnotetext{
${ }^{6} \mathrm{He}$ wrote (p. 4) that corresponding to the belief and attitude of a primary reason for an action, we can always construct (with a little ingenuity) the premises of a syllogism from which it follows that the action has some (as Anscombe puts it) 'desirability characteristic'. Thus there is a certain irreducible - though somewhat anaemic - sense in which rationalization justifies: from the agent's point of view there was, when he acted, something to be said for the action." Davidson goes on, in part III of that paper, to say that the fact that the reasons for an action justify it does not preclude their also being its causes - which was, of course, the central point that he was making in the paper.
} 


\section{Robert Pinto}

those desires is rationally obliged or committed to act in a certain way.

Despite the fact that the term "ought" seems to work well with some examples, I doubt that in general the reasons I have for performing an action "oblige me" to perform it. When it comes to actions, there are typically many ways to skin a cat and often any one of them will do. Even with respect to cognitive attitudes (beliefs, for example), to say that a person is obliged to believe everything she has reasons for believing - perhaps everything that "follows from" what she believes - seems like overkill. ${ }^{7}$ But there is something right in Brandom's approach: to ascribe to someone a reason for doing something is not to say the he or she will do it, but is rather to ascribe some kind of normative status to doing it. In the preliminary account of reasons that follows, I will characterize the normative status which reasons confer on doing what they are reasons for with the deliberately vague normative expression 'it is $\mathrm{OK}$ to do it' - where for starters to say that something is $\mathrm{OK}$ is to say that it merits or deserves approval. Only at the end of this paper will I try to bring into clearer focus what the particular "species" of being OK I'm talking about amounts to.

\section{What it is for one thing to be or provide a reason for another}

Consider first the following suggestion about what it is for the proposition that $\mathrm{R}$ to be a reason for holding that $\mathrm{Q}$

(1) $\mathrm{R}$ is a reason for holding that $\mathrm{Q}$ if and only if its being $\mathrm{OK}$ to hold that $\mathrm{R}$ would make it $\mathrm{OK}$ to hold that $\mathrm{Q}^{.8,9}$

7 To be fair to Brandom, he distinguishes between acknowledged commitments and consequential commitments (those commitments we have as a consequence of acknowledged commitments), which correspond roughly to two senses of belief. He says (1994, p. 195), "In one sense, one believes just what one takes oneself to believe, what one is prepared to avow or assert. In another sense, one believes, willy-nilly, the consequences of what one believes." And he suggests further (p. 196) that because of this ambiguity, "An unambiguous technical term 'doxastic commitment' is introduced, which comprises both commitments one is prepared to avow and commitments that follow from those one acknowledges."

${ }^{8}$ Why not, instead of invoking the idea of "making it OK to hold that Q," adopt something like the following formulation?

(1a) R is a reason for holding Q if and only if whenever it's OK to hold that R it is also $\mathrm{OK}$ to hold that Q. (1a) won't do, for the following reason. There may be propositions or propositional contents which it is always and everywhere OK to hold (e.g., 
In other words, the force of a reason for holding that $\mathrm{Q}$ lies in its power to make it $O K$ to hold that $\mathrm{Q}$.

Even though I think there is something importantly right about this first suggestion, there are two considerations each of which points to a need to revise the idea it expresses:

(a) it makes no provision for defeasible reasons, and

(b) it makes no provision for the idea that what provides a reason may be the confluence of a belief and a desire or pro-attitude or more generally the confluence of several propositional attitudes.

\section{Consideration (a)}

To suppose that $\mathrm{R}$ is a defeasible reason for holding that $\mathrm{Q}$ is to suppose that the force of $\mathrm{R}$ to make it $\mathrm{OK}$ to hold that $\mathrm{Q}$ can be "defeated" — can be undermined or overridden ${ }^{10}$ by — considerations that are consistent with the reason R. If and when such "defeating" considerations come to light,${ }^{11}$ holding that $\mathrm{R}$ no longer makes it

something like "self-evident truths" or things which it is OK to hold even in the absence of reasons, such as so-called "self-justifying" propositions). And if there are such - call one of them R! - then (1a) would commit us to the problematic idea that any proposition or propositional content is a reason for holding R!. This, of course, is an analogue of the principle that a necessary proposition is entailed by any proposition. (In my view, that principle is correct - and in my scheme of things provides additional grounds for concluding that R's being a reason for holding that $\mathrm{Q}$ is not to be equated with $\mathrm{R}$ 's entailing $\mathrm{Q}$.)

${ }^{9}$ Notice that if we were to assume that it is OK to hold that $\mathrm{P}$ if and only if it is true that $\mathrm{P}$, (1) would come close to an account of what it is to be a reason that deductivists might be comfortable with, namely:

(1b) R is a reason for holding that Q if and only if its being true that $\mathrm{R}$ would make it true that $\mathrm{Q}$.

${ }^{10}$ With Pollock, I recognize two types of defeaters - Pollock $(1970,1995)$ calls them undercutting defeaters and rebutting defeaters, I call them undermining and overriding. See also Raz (1978, pp. 12-13). In my account, where R is a defeasible reason for $\mathrm{Q}, \mathrm{D}$ is a overriding defeater which cancels the force of $\mathrm{R}$ if and only if (i) D is consistent with R and (ii) the conjunction of R and $\mathrm{D}$ is a reason for holding not-Q. D is an undermining defeater if and only if (i) D is consistent with $\mathrm{R}$ and (ii) the conjunction of $\mathrm{D}$ and $\mathrm{R}$ is not a reason for holding $\mathrm{Q}$ and is not a reason for holding not-Q.

${ }^{11}$ The power of certain considerations to undermine or override the force of a reason $\mathrm{R}$ cannot be simply a matter of the fact that the states of affairs with which those considerations are concerned are possible or even that they in fact obtain. This is most apparent in cases where those considerations override $\mathrm{R}$ by indicating that $\mathrm{Q}$ is false. (i) If $\mathrm{R}$ is a defeasible reason for holding that $\mathrm{Q}$, then it is possible that not-Q; so that if the mere possibility of something were enough to override the force of $\mathrm{R}$, the force of a defeasible reason would always be overridden. And (ii) if the mere fact that something incompatible with Q actually obtains overrides the force of $\mathrm{R}$ with respect to $\mathrm{Q}$, then the mere fact that $\mathrm{Q}$ is false will override the force of $\mathrm{R}$ - with the result that it wouldn't be possible to 
OK to hold that Q. Moreover, since a defeater may come to be available to one person but not come to be available to another, it will often turn out that a reason which makes it $\mathrm{OK}$ for one person to hold that $\mathrm{Q}$ does not make it $\mathrm{OK}$ for another person to hold that Q. In order to take defeasible reasons into account, then, we must replace (1) with something like

(2) $\mathrm{R}$ is a reason for holding $\mathrm{Q}$ if and only if, in the absence of considerations available to a person $S$ that would undermine or override the force of $\mathrm{R}$, its being $\mathrm{OK}$ for $\mathrm{S}$ to hold that $\mathrm{R}$ would make it $\mathrm{OK}$ for $\mathrm{S}$ to hold that Q

In this paper I will not attempt to spell out the conditions under which a defeating consideration is "available" to a person S, nor the conditions under which a consideration $\mathrm{D}$ undermines or overrides the force of a reason. ${ }^{12}$ In the literature that deals with defeaters there are contentious issues surrounding both of these questions that will have to be sorted out on another occasion. ${ }^{13}$

Note that as soon as we recognize that its being OK to hold that $\mathrm{Q}$ is relative to persons, we must abandon any attempt to

have defeasible reasons for conclusions which are in fact false. For these reasons, overriding considerations must be considerations which have "come to light" - considerations of which we are in some way aware, or perhaps of which we ought to be aware.

${ }^{12}$ A complicating factor arises when we recognize that a (potential) defeater can itself be defeated. Strictly speaking, a consideration D available to $S$, which potentially overrides the force of a reason $\mathrm{R}$, may itself be undermined or overridden by other considerations available to S. I would want to say that in such a case D itself would not count as a consideration that actually undermines the force of R. Things get more complicated still when we recognize the a consideration D1, which potentially defeats D, may itself be defeated -perhaps thereby "restoring" the status of D as an actual defeater of the force of R. I want to thank Scott Aikin of Western Kentucky University for reminding me of the bearing which such considerations have on how we must apply concept of "a consideration available to a person $\mathrm{S}$ that would undermine or override the force of R." See also Pollock (1995, chapter 3, section 6, especially 6.1 on p. 110) for one way of dealing with these complications in a context somewhat different from the context I am operating in.

${ }^{13}$ For a an overview of the issues to be faced in working out details of defeasible reasoning and about what is to be counted as a defeater, see Pollock (1995, esp. Chapters 2 and 3) and Koons (2009). Pollock (1995, chapter 3) offers a somewhat detailed overview of his account of defeasible reasoning in general and of defeaters in particular - worked out in the context of what he calls (p. 52) "epistemology from the design stance" ( i.e., "epistemological questions that bear on the design of a rational agent"). That Pollock is forced in chapter 3 to take a series of positions which are open to debate is evidence of the extent to which contentious issues surround questions about the proper characterization of defeaters. From my perspective, a serious drawback of Pollock's approach is that it requires quantification of the degree of support supplied by any prima facie reason to what it is a reason for (see note 4 above for my reservations about Pollock's approach to quantifying degrees of support). 
equate its being $O K$ to hold that $\mathrm{Q}$ with its being true that $\mathrm{Q}$, since its being true that $\mathrm{Q}$ is not relative to persons. ${ }^{14}$

\section{Consideration (b)}

In order to accommodate Davidson's idea that a reason for action consists of a belief and a pro-attitude, we can view (2) as a consequence of a still more general principle which provides for cases in which the confluence of someone's holding several propositional attitudes is what provides that person with a reason for doing something. We may take that more general principle to constitute a definition of what it is for something to provide a reason for something else. Here is a preliminary, if slightly complicated, version of that more general principle:

(3) Holding one or more cognitive, conative or evaluative attitudes toward various propositional contents provides a reason doing $\mathrm{X}$ if and only if, in the absence of considerations available to a person $\mathrm{S}$ that would undermine or override their force, its being $\mathrm{OK}$ for $\mathrm{S}$ to hold all of those attitudes would make it $O K$ for $\mathrm{S}$ to do $\mathrm{X}$

In this context, it is assumed (i) that doing $\mathrm{X}$ is either performing an action or is holding a cognitive, conative or evaluative attitude toward a specific propositional content, and (ii) that the attitudes in question may or may not be qualitatively different types of attitude.

For example, suppose Sam believes that Jones has been murdered and also believes that among Jones' acquaintances Smith had the strongest motive for murdering him. Its being OK for Sam to have those two beliefs taken together would, in the absence of a defeater, make it $O K$ for Sam to suspect that Smith murdered Jones - though they would not make it OK for Sam to be certain that Smith murdered Jones.

${ }^{14}$ Recognizing that its being OK to hold that $\mathrm{P}$ is relative to persons does not require us to make the relationship in virtue of which something is a reason for something else relative to persons. For we can insist on the following principle:

If the fact that it's OK for a particular person $\mathrm{S}$ to hold that $\mathrm{R}$ makes it $\mathrm{OK}$, in the absence of undermining or overriding considerations, for that person to hold $\mathrm{Q}$, then anyone's being entitled to hold that $\mathrm{R}$ makes it $\mathrm{OK}$, in the absence of undermining or overriding considerations, for him or her to hold that Q.

Whether the relationship in virtue of which something is a reason for something else holds over time is a more complicated matter. For example, it is plausible to suppose that at an earlier point in time the fact that Mr. Smith was both male and married was a reason for being sure that Mr. Smith had a wife. But in our time, when same sex marriages are not uncommon, it would seem no longer to be a reason for being sure that Mr. Smith has a wife (though it is still a reason for being sure that Mr. Smith has a spouse). 


\section{Robert Pinto}

Notice that in (3) I have shifted focus slightly - instead of saying of a proposition or statement that it is a reason, I am saying that holding one or more attitudes toward various propositional contents provides someone with a reason for doing something. ${ }^{15}$

On the basis of this account,

- Part 4 will formulate criteria for determining when a person has a reason - and has a good reason - for doing something,

- Part 5 will deal with how the attitudes which provide reasons are put into words

- And Part 6 will deal with how reasons come to be embedded in explanations, justifications and arguments.

\section{Having a reason}

Given the idea encapsulated in (3), we may formulate a criterion for determining when someone has a reason for doing something as follows.

(4) If (a) there is a set of one or more propositional attitudes of appropriate types which together provide a reason for doing $X$ and (b) a person $S$ holds each of those attitudes then $S$ has a reason for doing $X$

\footnotetext{
${ }^{15}$ Pryor (2007, pp. 217-218) recognizes three distinct "ontologies" of reasons that reasons are facts, that reasons are propositions and that reasons are attitudes or "states" such as beliefs and desires. He calls the third sort of ontology 'statism' and his paper is devoted to deconstructing certain arguments that can be advanced against statism and in favor of the view that reasons are propositions. Pollock (1995, p. 55) also explicitly endorses the view that what function as reasons are mental states rather then propositions. Though my sympathies are with those who endorse "statism" - I am personally prepared to identify reasons with conscious attitudes rather than with propositions - I don't want to make the story I'm telling here to hinge on "ontological" issues about reasons. Accordingly, I have phrased (3) in terms of "providing a reason", thereby hoping to sidestep the ontological issues.

I'm quite prepared to admit that where it is clear that we are talking about beliefs providing reasons for other beliefs, it is natural and useful to identify the reasons simply by referring to the propositional contents of those beliefs. I am also prepared to admit that facts, unknown to a person $\mathrm{S}$, can be called reasons for that person to act in a certain way. About cases where facts not known to an agent are called reasons for that agent to act in one or another way I would say: (i) in such cases there is a reason for $\mathrm{S}$ to act in such and such a way because a certain fact obtains, but S doesn't have a reason to act in that way merely because that fact obtains and (ii) a fact can be called a reason for a person $\mathrm{S}$ to act in a certain way if and only if it is the case that if $\mathrm{S}$ were to be aware of that fact then $\mathrm{S}$ would have a reason to act in that way. In other words, I would construe the sense in which facts can "be" reasons as derivative from the sense in which conscious states and attitudes are or provide reasons.
} 
If the reason which a person has is defeasible, ${ }^{16}$ we may want to say that she has a prima facie reason for doing what she has a reason for doing.

How should we describe cases in which a person does $X$ as a result of conscious attitudes which don't in fact "support" doing X? I suspect that most will want to describe them as cases in which a person has a defective reason. However, a few have given accounts of argument which seem to imply that such cases are best described as cases in which a person doesn't actually have a reason for what he does - see for example Blair (2004, p. 143) and Goldman's (1999, p. 131) account of what an argument is. ${ }^{17}$ For purposes of this paper, I shall adopt the second way of speaking, and will describe such cases as cases in which agents think they have a reason for doing X, but in fact lack a "genuine reason" for doing so. As far as I can see, adopting this way of speaking involves only a decision about linguistic usage and does not have substantive philosophical import.

In line with (4), we can formulate a criterion for having a good prima facie reason:

(5) If (a) there is a set of one or more propositional attitudes of appropriate types which taken together provide a reason for doing $\mathrm{X},(\mathrm{b})$ a person $\mathrm{S}$ holds each of those attitudes and (c) it is $O K$ for $\mathrm{S}$ to hold each of those attitudes then $\mathrm{S}$ has a good prima facie reason for doing $\mathrm{X}$.

Notice that even though $\mathrm{S}$ has a good prima facie reason for doing $\mathrm{X}$, it may not be $\mathrm{OK}$ for $\mathrm{S}$ to do $\mathrm{X}$ if considerations available to $\mathrm{S}$ undermine or override the force of that reason. Accordingly, with these criteria in mind we need to say what it is for a person to have a good reason all things considered:

(6) A person $\mathrm{S}$ has a good reason all things considered for doing $\mathrm{X}$ if and only if (a) $\mathrm{S}$ has a good prima facie reason for doing $X$ and (b) no considerations available to $\mathrm{S}$ undermine or override the force which that reason provides for doing $\mathrm{X}$.

\footnotetext{
${ }^{16}$ I.e., if there are conceivable considerations which, if they came to light, would undermine or override the force of what would otherwise make it OK to do something.

17 "A set of statements or propositions schematized as ' $R_{1} \ldots, R_{n}$, therefore $P$ " constitute what logicians and philosophers call an argument. It contains one or more premises and a conclusion, where the premises jointly supply evidential support (not necessarily conclusive)for the conclusion." From the preceding paragraph it clear that Goldman intends this definition of argument to apply to the verbal expression of a person's reasons for his or her beliefs.
} 
Let me stress again that to say it is $\mathrm{OK}$ for a person to do something is to make a normative claim. There is no guarantee that the person in question will do what he or she has a good reason all things considered to do. However, we might want to borrow a phrase from Siegel $(1988$, p. 2) and say that a person who is "appropriately moved by reasons" is likely to do what he or she has a good reason all things considered to do.

\section{Putting reasons into words}

When we offer our reasons for what we did or are about to do, or offer Sarah a reason for her to do something (e.g., to believe something), we put our reasons into words, typically in the form of declarative sentences. ${ }^{18}$ Indeed, Brandom (1994, p. 158) has claimed that "to offer a reason is always to make an assertion." How can we square the idea that reasons are typically put into words by uttering declarative sentences with the idea that what provides us with a reason is holding one or more cognitive, conative and/or evaluative attitudes?

These two ideas are compatible because when I make an assertion, either I describe myself as holding an attitude (saying, for example, 'I want to see my sister this afternoon') or else I represent myself as holding one or another attitude toward a propositional content. If I say without qualification, 'John is standing over there' I represent myself as believing that John is over there - as is apparent from the pragmatic inconsistency of 'p, but I don't believe that p'. If I say, 'Presumably, that's John standing over there', I represent myself as presuming that John is over there. 'Presumably' is just one of a class of "epistemic modals' which can be taken as indicators of the sort of cognitive attitude a speaker is adopting or thinks it is appropriate to adopt toward a propositional content.

It is perhaps worth noting that if I say "I am driving downtown because I want to see my sister this afternoon," what defeats the reason I've put forward typically are not considerations that undermine or override the force of my belief that I want to see my sister, but are rather considerations that undermine or override the

\footnotetext{
${ }^{18}$ Typically, but not always. David Godden and Jean Goodwin have each called my attention to cases in which a question or an imperative can be used to call a hearer's attention to a reason for doing something. In one of Goodwin's examples - "Look at your watch. It's time to go home" - speaker doesn't state a reason, but directs hearer to do something as a result of which heater will uncover a reason for supposing that it's time to go home. Ditto for "What time is it? Perhaps we should head home." Rhetorical questions represent still another sort of case in which a sentence having the form of a question may be used to convey a reason.
} 
force of my wanting to see my sister as a reason for driving downtown. What I am offering as a reason for driving downtown is not the belief that I have a certain want but rather that very want itself.

It is important to note another aspect of what happens when I make an assertion - namely that in asserting that P I typically invite those I'm addressing to adopt the attitude that I represent myself as adopting - and in many cases I can be viewed as licensing them to adopt that attitude. ${ }^{19}$ In saying to Sarah, "Presumably, Sam is no longer married' I invite Sarah to presume that Sam is no longer married and perhaps license her to so presume. And if the presumption that Sam is no longer married provides a reason for presuming that Sam is either widowed or divorced, then I will have offered Sarah a reason for so presuming. It is because of considerations like these that Brandom (1994, p. 168) is on the right track when he says, "assertions are fundamentally fodder for inferences. Uttering a sentence with assertional force or significance is putting it forward as a potential reason."20

\section{What can be accomplished by putting reasons into words}

When a speaker puts reasons into words, he or she is often presenting those reasons as reasons for doing one or another specific thing. Those reasons may be presented as reasons for the speaker to do this or that. Or else they may be presented as reasons for one or more hearers to do this or that - for example, as reasons for hearers to believe a conclusion.

(a) Consider first those cases in which a person gives her reasons for what she is doing or has done.

Sally may offer $\mathrm{R}$ as a reason for her to believe that $\mathrm{Q}$, or to suspect that $\mathrm{Q}$, whether or not it is $O K$ for her to hold that $R$. And others may take her to have offered $R$ as a reason for believing that $\mathrm{Q}$ even if they have no idea whether it's OK for her to hold that R indeed even if they think it's not OK for her to hold that R. In order for others to take Sally to have offered a reason for holding that $\mathrm{Q}$, all that is necessary is for them to think that if it should be

19 I.e., in those cases in which the speaker can be viewed as "taking responsibility" for the soundness of what she has put forward for acceptance by the hearer. I'm indebted to Jean Goodwin for this point.

20 The passage continues, "Asserting is giving reasons - not necessarily reasons addressed to some particular question or issue, or to a particular individual, but making claims whose availability as reasons for others is essential to their assertional force. Assertions are essentially fit to be reasons. The function of assertion is making sentences available for use as premises in inferences." 
OK for Sally to hold that R, then in the absence of a defeater its being OK for her to do so would make it OK for her to hold that Q.

What a speaker accomplishes by articulating her reasons for what she has done or is about to do depends on what has prompted her to articulate those reasons. For example, where it is clear that speaker gives reasons in response to or in anticipation of a question like "Why did you do that?" a hearer who takes what she said to provide a reason for doing what she did will take her to be explaining what she did. Whether a hearer will take such an explanation to be a good explanation will depend largely on whether hearer thinks the speaker in fact acted because she held the attitudes which she invoked as providing a reason. The goodness or success of someone's explanation for what she did does not seem to depend on whether the reasons proffered are good reasons (in the sense 'good reason' defined above).

On the other hand, where it is clear that the speaker's reasons are given in response to or in anticipation of someone criticizing or condemning him for what he did, a hearer who takes what was said to be a reason for the speaker to have done what he did will normally take him to be attempting to justify what he did. If Sam has been criticized or condemned for doing such-and-such, he can respond to the criticism by saying, "I did (or am doing) such-andsuch because I thought (or think) that R" - e.g. "I think that tomorrow is Friday because I know that today is Thursday" or "I refused to talk to him because I'd heard that he called me a thief."

PJ1 Where it is clear that people state their reasons for doing something in response to or anticipation of criticism or condemnation of what they did, they can be viewed as attempting to justify what they did. ${ }^{21}$

\footnotetext{
${ }^{21}$ Interestingly enough, this account of justifying is consistent with Brandon's account of the role of justification in the "game of giving and asking for reasons." According to Brandom (1994, p. 173) those who produce assertions not only "authorize" further assertions by themselves and their audience (see note 20 above), but they also undertake "a specific task responsibility, namely the responsibility to show that they are entitled to the commitment expressed by their assertions, should that entitlement be brought into question." This is a matter, of course, of showing or demonstrating that it is $O K$ for them - the speakers - to be committed to what they've asserted: where what they've asserted is that $\mathrm{P}$, it is a matter of showing it is OK for them to believe that P. "This," Brandom says, "is the responsibility to do something, and it may be fulfilled for instance by issuing other assertions that justify the original claim." But as is made clear in the pages that follow, which describe the default and challenge structure of entitlement (pp. 176-78), the need to produce a justification arises only "when a challenger is entitled to the challenge" (p. 178). For more about Brandom's account of the default and challenge structure of entitlement and its implications, see point (3) in note 25 below.
} 
Attempted justifications differ from explanations in that justifications aren't judged successful unless the reasons put forward are good reasons - e.g., unless the attitudes cited as providing a reason are attitudes the agent was entitled to have at the time he or she acted.

PJ2 Where people state their reasons for doing something in an attempt to justify their doing it, and it is or can be made clear that they were entitled to the attitudes which provided them with those reasons, they have presented a prima facie justification of what they did.

Of course a prima facie justification can be undermined or overridden by other considerations. Where we think that speaker was aware or ought to have been aware of those considerations, it is unproblematic to say simply that that the speaker's attempt to justify what she did fails. But suppose we are aware of considerations that defeat the prima facie justification, but don't think the speaker was or ought to have been aware of them. It isn't completely clear to me what we should say in such a case perhaps we should say only that the speaker has shown she had a good excuse for doing what she did.

Finally, I should make it clear that these remarks concern only sufficient conditions for determining when giving a reason should count as an explanation or as a justification. Clearly the conditions I've pointed out are not necessary conditions. For example, I can explain or attempt to justify what somebody else did, not just what I did. And though I personally am sceptical about the wisdom of using the word 'justification' in connection with reason-giving not offered in reply to or anticipation of condemnation or challenge, such usage is commonplace among philosophers and even among argumentation theorists. I harbour no totalitarian desire to legislate how others may use that word.

(b) Consider next cases in which a speaker intends to offer one or more hearers a reason for them to do some specific thing. That, it seems to me, is what is typically going on when speaker says something of the form ' $R$, so Q', saying, perhaps,

Today is Thursday, so there are two more days between today and Sunday

or

The movie we want to see starts in half an hour, so let's leave now' 


\section{Robert Pinto}

Hearers will construe what speaker has said as an argument just when (i) within the transaction in which they are involved, what speaker has given a reason for is something about which there is disagreement or doubt and (ii) hearers take what comes before the 'so' to be a reason for what comes after it. Moreover, a speaker can be seen to be making or presenting an argument without uttering an "indicator" word such as 'so' or 'therefore' or 'because.' For example, in a context in which a question has implicitly or explicitly been raised about whether it is the case that $\mathrm{Q}$, those who take $\mathrm{R}$ to be a reason for supposing that $\mathrm{Q}$ are likely to construe a speaker's assertion that $\mathrm{R}$ to be an attempt to present an argument for supposing that Q.

It is important to note that in the sorts of cases just described, construing speaker to have presented an argument for $\mathrm{Q}$ does not require attributing to the speaker any specific purpose beyond that of presenting a reason for doing some specific thing-for example, there is no need to suppose that speaker is trying to persuade someone of $\mathrm{Q}^{22}$ or trying to resolve a difference of opinion (see Pinto 2003 and Goodwin 2007).

Where, as in the examples above, $\mathrm{R}$ in fact provides a reason for doing what a speaker presents it as a reason for doing, anyone who says to another ' $\mathrm{R}$, so Q' will in fact have offered that other person a reason - perhaps for believing that $\mathrm{Q}$, or for acting in a certain way. But how we describe the "transaction" between speaker and hearer depends on what we think hearer makes of what speaker said.

If we think hearer has come to accept that $\mathrm{R}$ as a result of what speaker said, it is unproblematic to say that speaker has given hearer a reason for believing that $\mathrm{Q}$ or for leaving now, and we should be prepared to say that hearer now has a reason (at least a prima facie reason) for doing so (though not necessarily a good prima face reason). If hearer had already accepted $\mathrm{R}$, but only now comes to see that $\mathrm{R}$ is a reason, e.g., for believing that $\mathrm{Q}$, we might want to say that speaker has made hearer realize that she has a reason for believing that $\mathrm{Q}$. If hearer doesn't accept $\mathrm{R}$ (doesn't take speaker up on her offer), it becomes problematic to say that speaker has given him a reason to believe that $\mathrm{Q}$ or to leave now since, for all we know, having refused to accept $\mathrm{R}$, speaker may have no reason for doing what speaker presented him with a reason

\footnotetext{
${ }^{22}$ The view I put forward in Pinto 2001 (chapter 4) that arguments are invitations to inference traded on the idea that we call something an argument just when the arguer it trying to get a hearer to accept a conclusion by presenting him with a reason for adopting that conclusion. Though I still think that view of argument correct insofar as it pictures arguers a offering others reasons for them to do this or that, I now think that view was too narrow in assuming that arguments are always attempts at persuasion - i.e. that arguer's are always trying to get hearers to accept an argument's "conclusion". See Pinto 2003.
} 
for doing. If hearer doesn't accept $\mathrm{R}$, a discussion may ensue about whether hearer should accept $\mathrm{R}$ - a discussion in which speaker and hearer may begin by trading reasons for and against accepting $\mathrm{R}$.

Even if hearer accepts $\mathrm{R}$, he may or may not take $\mathrm{R}$ to be a reason doing $\mathrm{X}$ (e.g., believing that $\mathrm{Q}$ or leaving now for the movie). For example, hearer may have counted up the days incorrectly, and think that if today is Thursday then there are three more days between today and Sunday, or hearer may think it doesn't matter whether one gets to a movie before it begins. If hearer doesn't take $\mathrm{R}$ to be a reason for doing $\mathrm{X}$, he won't think that speaker has presented him with a reason for doing it, and a discussion may ensue about whether $\mathrm{R}$ is in fact a reason for doing it.

Furthermore, hearer may accept $\mathrm{R}$ and take $\mathrm{R}$ to be a reason for doing $\mathrm{X}$, but hearer may be aware of considerations which undermine or override the force of $\mathrm{R}$ as a reason for doing it.

In this event, hearer may concede $\mathrm{R}$ and concede that $\mathrm{R}$ is a prima facie reason for doing $\mathrm{X}$, but in light of the undermining or overriding considerations may not take it to be a reason all things considered for doing X. Hearer may or may not explain his refusal to accept $\mathrm{R}$ as an all things considered reason by explicitly stating those undermining or overriding considerations. If he does so, a discussion may ensue about (i) whether the considerations to which hearer calls attention really do undermine or override the force of $\mathrm{R}$ or (ii) whether it is $\mathrm{OK}$ to give standing to those considerations.

Alternatively, it may not dawn on hearer that he is aware of considerations which undermine or override the force of R. In that event hearer may take $\mathrm{R}$ to be an all-things-considered reason for doing $\mathrm{X}$, even though it is some kind of mistake for him to do so.

Finally, if it is $O K$ for you to accept that R merely on my sayso, then in saying ' $R$, so Q' I have given you - put you in the position of having - a good prima facie reason for accepting $\mathrm{R}$. And if no considerations are available to you which undermine or override the force of $\mathrm{R}$, I have given you a good reason all things considered and thereby made it $\mathrm{OK}$ for you to believe that $\mathrm{Q}$.

In Pinto $\left(2003\right.$, p. 1) I wrote that the first or primary effect ${ }^{23}$ of presenting an argument

${ }^{23}$ In that paper I recognized secondary and tertiary effects that might or might not flow from an argument's primary effect - and which a speaker may or may not be aiming at in presenting her argument. For example, making it manifest to Sam that there is a reason for him to call Sarah might result in Sam's forming an intention to call her (a secondary effect of the argument presented). And Sam's intention to call Sarah might result is his actually calling her (a tertiary effect of the argument presented). 
consists in making it manifest to participants in a communicative context (i) that there is a reason for doing something and (ii) what one such reason is.

In keeping with that idea we could say that normally someone who presents an argument aims at the very least to make it manifest to those addressed that it is, or may be, OK for them to do what that argument presents them with a reason for doing.

\section{Taking something to be a reason}

Participants in a conversion could not view what transpires in that conversation as explanations or justifications or arguments unless, correctly or incorrectly, they took certain statements or attitudes to be or to provide reasons for doing one or another specific thing.

Moreover, the standards or norms in light of which an individual or community assesses whether it is $\mathrm{OK}$ for someone to do something are implicit in what they take to be reasons for doing it - implicit because one can take something to be a reason without saying that it is a reason. Those norms become explicit when such takings are challenged and discussion ensues about whether what has been taken to be a reason ought to be taken to be reason for this or that. When such discussion transpires, a space opens up in which the difference between our taking something to be or provide a reason and its actually being or providing a reason makes its presence felt.

A hearer who questions whether something is or provides a reason may or may not explain why she doesn't accept it as being or providing a reason. Let me offer two examples in which hearer offers an explicit reason for calling into question whether what speaker has proffered as a reason for doing something is a genuine reason for doing it.

Example 1. Speaker says, "There was heavy rain half an hour ago, so the streets must be wet," and hearer responds by saying, "But it doesn't usually take more than a few minutes for the streets to dry after a rain shower." Hearer has made it clear that she doesn't take what speaker presented as a reason to be a genuine reason, and does so by offering a reason for not accepting the proffered "premiss" as a reason for believing that the streets are wet.

Notice that the speaker can dispute the rejoinder, perhaps citing studies in which measurements have been taken of the mean times it takes for streets to dry after various sorts of rain storms. 
Example 2. Speaker says, "Sarah accepted our invitation to the dinner we're having tonight, so presumably we'll see her tonight." Hearer says, "Don't presume that. People frequently accept invitations and then don't show up."

Here again speaker can dispute the rejoinder - perhaps by pointing out for starters that presuming something will happen is not the same as counting on it to happen. Notice that at the heart of such a dispute would be the question of what sort of reason or evidence makes it sensible to presume that something will occur.

In short, such challenges and the discussions they give rise to can be rational in the sense that challengers or discussants can support what they say about reasons with reasons and, with luck, can reach agreement based on the reasons they exchange. What is explored in such discussions is what Toulmin calls the backing from which "warrants" get their force; and Weinstein (2006) would surely point out that full exploration of such backing is often a complex undertaking indeed.

In example 1 the issue of whether the "premiss" advanced provides a reason for believing or expecting a particular outcome turns largely on factual matters open to empirical investigation. But that is not the whole story. The issue of whether that premiss provides a reason - whether its being OK to accept the premiss makes it $O K$ to believe or expect a certain outcome - is a normative issue whose resolution may depend crucially on factual matters but which cannot depend only or wholly on factual matters. In my view, Toulmin (2003/1958, p. 98) gets it basically right when, distinguishing between a warrant and its backing (which in the example he was discussing had consisted of facts about British statutory law which lay down requirements for being a British citizen), he said

Though the facts about the statute may provide all the backing required by this warrant, the explicit statement of the warrant itself is more than a repetition of these facts: it is a general moral of a practical character, about the ways in which we can safely argue in view of these facts.

Example 2 brings this point more out clearly, I think. The frequency with which those who accept invitations actually turn up certainly has a bearing on whether somebody's having accepted an invitation makes it $\mathrm{OK}$ to presume that they will turn up. But whether or not frequency in a given range makes it $\mathrm{OK}$ to so presume depends just as crucially on the practical implications of 
presuming - on what further things its being $\mathrm{OK}$ to presume that $\mathrm{P}$ makes it OK for us to do. ${ }^{24}$

Two important conclusions should be drawn from these considerations:

(a) The mere fact that something is taken to be a reason does not mean that it is a reason - a person or, for that matter, an entire community can be wrong with respect to what is a reason for what.

(b) Although matters of fact typically have a crucial bearing on what is a reason for what, the question of whether something is or provides a reason for something else is always a normative question and cannot be settled by facts alone.

\section{What kind of normativity is this?}

As a matter of fact, in the course of this exposition I have been putting flesh on the skeletal idea from which I started - the idea of its being $\mathrm{OK}$ for someone to do something. In the story I've told I've explicitly restricted the intended application of 'it's OK for $\mathrm{S}$ to do $\mathrm{X}$ ' to only two categories of doing: to actions performed by

${ }^{24}$ In two recent papers I've tried to shed light what makes a warrant valid or OK, trying to show this depends crucially on what it is that various doxastic attitudes commit us to and on the purposes for which we reason.

In Pinto 2006 (p. 268) I suggested that cognitive attitudes such as believing, expecting, presuming, and so on, can be type-identified by reference to their functional role in our cognitive lives. I went on (pp.304-306) to suggest something that amounts to this: whether evidence of a certain sort warrants a given cognitive attitude toward a specific type of propositional attitude depends on whether the practice of adopting such an attitude toward such propositional contents on the basis of such evidence would serve the role that the practice plays in out our cognitive lives. In Pinto 2007 I tried to show how a functional analysis of the cognitive attitude of expecting could help us make sense of an idea drawn from Sellars, as modified by an observation made by Carnap namely, that to ascribe non-metric probability to a proposition is to say that it is reasonable all things considered to expect that that proposition will turn out to be true.

I am currently inclined to think that deciding whether to recognize the validity of a warrant - deciding whether a given "body of evidence" licenses the adoption of a given doxastic attitude toward a given propositional content depends less on the purposes served by the inferences endorsed by the warrant and more on the role which the licensed doxastic attitude plays in our conscious lives. I see the "epistemic modals" with which we qualify our assertions or claims as indicating the doxastic attitudes we take or ought to take toward the propositional content of what we say, and I maintain in Pinto (2007, p. 4), "it is not difficult to see how [the practical] implications [of epistemic modals] are readily construed as epistemically normative considerations."

However, what I'm saying in this paper doesn't depend on accepting the details any particular story about the grounds on which we adopt a warrant - i.e. the grounds on which we ought to decide whether this is a reason for that. 
specific individuals and to holding cognitive, conative and evaluative attitudes having specific propositional contents. Moreover, I have explicitly restricted the grounds for its application to criteria of a certain type - criteria which turn on there being an appropriate relationship of the doing being evaluated to cognitive, conative and/or evaluative attitudes toward propositional contents held by the individuals whose doing is being evaluated. Finally, I have portrayed the appropriateness of such relationships as something to be settled by rational discussion of a certain sort - discussion in which factual and normative considerations are brought to bear on the question of whether its being $\mathrm{OK}$ to do one sort of thing makes it $\mathrm{OK}$ to do another sort of thing.

I submit that in light of these restrictions what is picked out by the intended application of 'It's OK for $S$ to do $X$ ' constitutes a recognizable species of meriting approval.

$$
* * *
$$

Notice that it follows from (3) and (6) that

(7) If $S$ has a good reason all things considered to do $X$, then it is $\mathrm{OK}$ for $\mathrm{S}$ to do it.

However, the converse of (7), namely

(8) It is OK for $\mathrm{S}$ to do $\mathrm{X}$ only if $\mathrm{S}$ has a good reason all things considered to do it.

is problematic, since nothing in the account I've offered so far makes any obvious provision for avoiding an infinite regress of reasons that might be required if (8) were to be accepted. ${ }^{25}$ I

25 The problem of avoiding an infinite regress of reasons is a problem any epistemology must face. A variety of such strategies is available in the literature. (1) One strategy is to recognize what Pryor (2005) calls "immediate justification" - see note 26 below for the details. (2) Another quite intriguing attempt to avoid the problem can be found in Jonathan Adler's account of "tacit confirmation" in Chapter 6 of Belief's Own Evidence (Adler 2002) - an account which Adler thinks enables him to avoid falling back on either a foundationalist or a coherentist epistemology. (3) Still another approach can be found in Brandom (1994, pp. 176-178), who claims (p. 177) that "the social practices that govern the giving and asking for reasons...need not be - and the ones that actually confer content on our utterances are not - such that the default entitlement status of a claim or assertional commitment is to be guilty till proven innocent." Brandon goes on to say, "If many claims are treated as innocent until proven guilty - taken to be entitled commitments until and unless someone is in a position to raise a legitimate question about them - the global threat of regress dissolves." He calls this "a default and challenge structure of entitlement." (4) A fourth strategy is to maintain that being in a doxastic state which is the result of a "reliable belief forming mechanism" is justified. As a matter of fact, Brandom (1994, pp. 213-229 adopts a complicated variant of this strategy with respect to 
currently lean toward enhancing the account offered here so as to permit us to recognize regress stoppers - so that, for example, things like perceptual experiences could be said to provide good prima facie reasons for adopting certain cognitive attitudes ${ }^{26}$ or the fact of having enjoyed one sort of thing more than another could provide a good prima facie reason for preferring things of the first sort to things of the second. ${ }^{27}$ But I will leave the attempt at such enhancements for another occasion.

Enhancing the account of reasons so that (8) becomes acceptable would permit us to equate its being $\mathrm{OK}$ to do $\mathrm{X}$ with having a good reason all things considered to do it. Of course, taking that equation to be a definition would be viciously circular -

perceptual reports. However, in Brandom's account the ascription of entitlement to reliable perceptual reports is based on reasons which those who ascribe such entitlement have.

${ }^{26}$ See Pollock (1995, pp. 52-55, especially principle 2.2 on p. 55), who argues that it is perceptual experience itself (in his terminology, "having an image"), and not beliefs about perceptual experience, which constitute the prima facie reasons for many of our beliefs about our immediate environment. And see also the careful and insightful discussion of "immediate" or "non-inferential" justification in Pryor (2005). Pryor woks with a notion of justification (explained in Part I of draft 9), and is concerned basically only with the justification of beliefs. Despite these restrictions, what he has to say can be made relevant to the themes in this paper. Pryor says, "When your justification to believe P does not come from your justification to believe other propositions, I'll call it immediate" (p. 3 of draft 9) In his view, "the best argument [for immediate justification] comes from considering examples" ( $\mathrm{p} .6 \mathrm{of}$ draft 9). Part IV of the draft contains an extensive discussion of whether experiences - and he points out on p. 11, that "unlike beliefs, experiences aren't the sort of thing which could be, nor do they need to be, justified" - can be thought to justify beliefs. The basic thrust of the case he makes in Parts IV and V is to undermine what he takes to be the principal arguments against the supposition that experiences can justify beliefs.

${ }^{27}$ In his account of the logical structure of practical rationality, Pollock (1995, pp. 12-32) accords crucial roles to situation-likings and feature-likings. He says (p. 12), for example, "Situation-likings provide the ultimate starting point for rational deliberation. These are not representational states - the agent need not be thinking about the way things are. Situation-liking is a feeling rather than a propositional attitude." He ties feature-likings to our ability to "react conatively to imagined situations" and says, "As such, our reaction to these imagined situations constitutes a conative response to situation types rather than situation tokens., although it is not clear that these two kinds of likings should be regarded as genuinely different kinds of mental states" (p.20). Pollock use of the word "conative" is, I think, different from mine - I would see what he is calling 'likings' as mental occurrences that can give rise to and justify evaluate attitudes. For me, conative attitudes arise only when, on the basis of evaluative attitudes, we adopt something as a goal and adopt plans to achieve such goals. Pollock himself recognizes something like this distinction when he says (p. 23), "Goals are chosen on the basis of their expected likabilities...." Though there are many features of Pollock's account of practical reasoning I don't agree with, his idea that situation-likings and feature-likings are not propositional attitudes, but are capable of grounding evaluative propositional attitudes strikes me as a very promising idea. For useful summaries and assessments of Pollock's account of practical reasoning, see Hitchcock (2002) and Girle et al. (2003). 
since what it is to be a reason has been explained in terms of its being $\mathrm{OK}$ to do $\mathrm{X}$. But there would be no need to take the equation as a definition. $^{28}$

Notice also that apart from one complication, ${ }^{29}$ if we could accept (8) we might be able to equate this species of its being $O K$ for someone to do something with its being reasonable for him or her to do it.

\section{Conclusion}

Does this account of reasons shed any light on why there are different "cultures of theorizing" about argumentation - theorizing about practices which turn on the presentation and exchange of reasons? In particular, does it help to understand the existence of the triad Tindale calls attention to - the logical, dialectical and rhetorical perspectives? I think that to some extent we can see each of these three perspectives arising out of an emphasis on one or another aspect of what I've tried to describe in this general account of having and giving reasons.

(a) The varieties of logical perspective tend to emphasize questions about what is a reason for what. Of course, when an informal logician like Ralph Johnson (2000) insists that arguments (or at least good arguments) must have a dialectical tier as well as a an illative core, the concept of what is involved in presenting an argument becomes more complex than the account that was offered in Part 6 above.

(b) The value of making dialogue the preferred context for studying argumentation - which might be seen as lying at the heart of dialectical perspectives - is, to my mind, most clearly seen when we recognize the important effect that undermining

${ }^{28}$ In "The Folly of Trying to Define Truth", Davidson (1996/2005, esp. pp. 2021 and 36-37) claims - correctly I think - that when it comes to the very fundamental notions in terms of which we understand ourselves, definition is out of the question. Each of them is too basic to be defined in terms of anything more basic, but none of them is intelligible except by reference to the others the best we can hope for is to illuminate the ways in which they are related to each other.

${ }^{29} \mathrm{I}$ 'm inclined to think we ought to require that an additional condition be met before we deem it reasonable for a person to adopt an attitude A toward the idea that P. A person may have good, undefeated reasons for adopting an attitude A only because that person failed to make inquiries she or he should have made inquiries that would have or could have brought to light considerations which undermine or override his or her reasons for adopting A. For purposes of this paper, I have not attempted to recognize this as a requirement for its being $\mathrm{OK}$ to do $\mathrm{X}$. And without such a requirement it's probably not defensible to equate 'reasonable for S to do X' with 'OK for S to do X'. 
and overriding considerations have on the force of reasons. For it is discussions between and among two or more participants that provide contexts in which such considerations most readily come to light (as is evidenced in Rescher 1977, especially chapter 1.).

(c) The value of emphasizing the effect of argument on audience which if we follow Tindale 1999 is at the heart of rhetorical perspectives - though not immediately obvious on an account like mine which insists that the force of reasons is a normative force, is nevertheless quite real, and for the following reason. If an argument fails to persuade an audience, the fault may lie in the audience's failure to accept what they see it is reasonable for them to accept, or it may lie in arguer's failure to make it manifest to the audience that it is reasonable for them to accept what the arguer wants them to accept. Adopting a rhetorical perspective requires getting clear about what it will take to get an audience in a proper frame of mind to accept what they'll be shown it is reasonable to accept ${ }^{30}$ as well as getting clear about what it will take to make it manifest to the audience that it is reasonable to accept what the arguer wants them to accept. ${ }^{31}$

Acknowledgements: This is the full text, somewhat revised, of a keynote address presented at a conference of the Ontario Society for Studies in Argumentation held at the University of Windsor in June of 2009. I'm indebted to Jean Goodwin, Ralph Johnson and Harvey Siegel for critical comments on various drafts of the paper and to David Godden and Scott Aiken for comments and suggestions occasioned by the presentation of the shorter version of the paper delivered at the conference. The paper has been significantly improved as a result of the feedback from each of these individuals.

\footnotetext{
${ }^{30}$ See for example the Jacobs (1999, p. 400): “....argumentation theory should be concerned with the way in which argumentative messages enhance or diminish the conditions for their own reception. Argumentative messages may be designed either to open up or to close down the free and fair exchange of information. Argumentative messages may be designed either to encourage or to discourage critical scrutiny of the justification for alternative positions. I think one of the real insights of normative pragmatics is that argumentation is selfregulating and self-sustaining in just this way."

${ }^{31}$ See for example Pinto (2003, section 9): "Someone who presents an argument can fail to achieve [its] primary effect if his presentation is unclear, muddled, cryptic, insufficiently articulated, and so on. In such cases, the reason he is attempting to float will not be manifest (i.e., 'readily perceived by the eye or the understanding')." See O'Keefe (2002a, chapter 9; 2002b, esp. pp 76-77; and 2003) for summaries of what empirical research has shown to be the difference that clear and precise expression makes to the persuasive effect of arguments.
} 


\section{References}

Adler, Jonathan (2002). Belief's Own Ethics. Cambridge, MA: MIT Press.

Alston, William (2005). Beyond Justification: Dimensions of Epistemic Evaluation. Ithaca and London: Cornell University Press.

Barth, Else M, and Erik C.W. Krabbe (1982). From Axiom to Dialogue. Berlin and New York: Walter de Gruyter.

Blair, J.Anthony (2004). Argument and its uses. Informal Logic 24.2, pp. 137-151

Brandom, Robert B. (1994). Making It Explicit. Cambridge, MA: Harvard University Press.

Davidson, Donald (1963/2001). Actions, Reasons, and Causes. Journal of Philosophy. 60. Reprinted in Davidson 2001, pp. 319. Page references are to Davidson 2001.

Davidson, Donald (1997/2005). The Folly of Trying to Define Truth. Journal of Philosophy 94, pp. 263-78. Reprinted in Davidson 2005, pp. 19-36. Page references are to Davidson 2005.

Davidson, Donald (2001). Essays on Action and Events, Second Edition. Oxford: Clarendon Press.

Davidson, Donald (2005). Truth, Language and History. Oxford: Clarendon Press.

Eemeren, Frans H. van and Rob Grootendorst (1992). Argumentation, Communication, and Fallacies. Hillsdale, NJ: Lawrence Erlbaum Associates.

Chisholm, Roderick (1977). Theory of Knowledge, $2^{\text {nd }}$ edition. Englewood Cliffs, NJ: Prentice Hall.

Dennettt, Daniel C. (1996) Kinds of Minds: Towards an Understanding of Consciousness. London: Weidenfeld \& Nicolson.

Dennettt, Daniel C. (2006). "The Evolution of AWhy?: Essay on Robert Brandom, Making it Explicit'. Available on line at http://ase.tufts.edu/cogstud/papers/Brandom.pdf .

Dennettt, Daniel C. (1978). Brainstorms. Cambridge, MA: MIT Press.

Feldman, Richard and Earl Conee (1985). Evidentialism. Philosophical Studies, Vol. 48, pp. 15-34.

Girle, Roderick, David Hitchcock, Peter McBurney, and Bart Verheij (2003). Decision support for practical reasoning: A theoretical and computational perspective. In Christopher Reed and Tim J. Norman (eds.), Argumentation Machines: New Frontiers in Argumentation and Computation, Argumentation Library volume 9, pp. 55-83. Dordrecht: Kluwer. 


\section{Robert Pinto}

Goldman, Alvin (1999). Knowledge in a Social World. Oxford: Clarendon Press.

Goodwin, Jean (2002). One question, two answers. In Hansen et al., Proceedings of the Fourth OSSA Conference: Argumentation and its Applications (Windsor, Ontario: OSSA. CD. ISBN: 0-9683461-2-X).

Goodwin, Jean (2007). Argument has no function. Informal Logic 27: 1, pp. 69-90.

Hamblin, Charles L. (1970) Fallacies. London: Methuen.

Hitchcock, David (2000). Statement on practical reasoning. Available at: http://www.csd.abdn.ac.uk/ tnorman/sac/Hitchcock.doc.

Hitchcock, David (2002). Pollock on practical reasoning. Informal Logic 22, pp. 247-256.

Jacobs, Scott (1999). Argumentation as Normative Pragmatics. In Frans H. van Eemeren, et al., eds., Proceedings of the Fourth International Conference of the International Society for the Study of Argumentation, pp. 397-403. Amsterdam: SicSat.

Johnson, Ralph H. (2000). Manifest Rationality: A Pragmatic Theory of Argument. Mahwah, NJ: Lawrence Erlbaum Associates.

Koons, Robert (2009). Defeasible Reasoning. Stanford Encyclopaedia of Philosophy: http://plato.stanford.edu/entries/reasoning-defeasible/.

O'Keefe, Daniel J. (2002a). Persuasion: Theory and Research, $2^{\text {nd }}$ edition. Thousand Oaks, CA: Sage Publications.

O'Keefe, Daniel J. (2002b). The persuasive effects of variation in standpoint projection. In Frans H. van Eemeren, ed., Advances in Pragma-Dialectics, pp. 65-82. Newport News, VA: Vale Press / Amsterdam: Sic Sat.

O'Keefe, Daniel J. (2003). News for argumentation from persuasion effects research: Two cheers for reasoned discourse. Paper presented at the Thirteenth National Communication Association/American Forensic Association Alta Conference on Argumentation, Alta.

Pinto, Robert C. (2001). Argument, Inference and Dialectic. Dordrecht: Kluwer Academic Publishers.

Pinto, Robert C. (2003). The Uses of Argument in Communicative Contexts. In J.A. Blair, D. Farr, H.V. Hansen, R.H. Johnson and C.W. Tindale (Eds.), InformalLogic@ 25: Proceed-ings of the Windsor Conference. CD-ROM published by Ontario Society for the Study of Argumentation. A draft of a revised version of this paper is available at:

http://web2.uwindsor.ca/courses/philosophy/pinto/papers.htm.

Pinto, Robert C. (2006). Evaluating inferences: the nature and function of warrants. Informal Logic 26, pp. 287-317. Reprinted 
in D. Hitchcock \& B. Verheij (eds.), Arguing on the Toulmin Model, pp. 115-143. Dordrecht: Springer.

Pinto, Robert C. (2007). 'Probably' and other modal qualifiers. An extended abstract of this available in Dissensus and the search for common ground: Proceedings of OSSA 2007 (Windsor, Canada). A draft of a revised version of the paper is available at: http://web2.uwindsor.ca/courses/philosophy/pinto/papers.htm.

Pollock, John L. (1970). The Structure of Epistemic Justification. American Philosophical Quarterly, monograph series 4, pp. pp. 62-78.

Pollock, John L. (1995). Cognitive Carpentry: A Blueprint for How to Build a Person. Cambridge, MA/London: MIT Press.

Pryor, James (2005). There is immediate justification. In Steup and Sosa, eds., Contemporary Debates in Epistemology. Oxford: Blackwells. Link to draft 9. final draft of this paper, can be found on Pryor's Web at http://www.jimpryor.net/research/index.html.

Pryor, James (2007). Reasons and that-clauses. Philosophical Issues 17 (2007), pp. 217-244.

Raz, Joseph (1978). Practical Reasoning. Oxford: Oxford University Press.

Rescher, Nicholas (1977). Dialectic: A Controversy-Oriented Approach to the Theory of Knowledge. Albany: State University of New York Press.

Rescher, Nicholas (1988). Rationality. Oxford: Clarendon Press.

Siegel, Harvey (1988). Educating Reason: Rationality, Critical Thinking and Education. New York and London: Routledge.

Tindale, Christopher W. (1999). Acts of Arguing. Albany: State University of New York Press.

Toulmin, Stephen (2003/1958). The Uses of Argument, Updated edition. Cambridge: Cambridge University Press. The first edition of this work was published in 1958. Page references are to the updated edition.

Walton, Douglas N. and Eric C.W. Krabbe (1995). Commitment in Dialogue. Albany: State University of New York Press.

Weinstein, Mark. (2006). A Metamathematical extension of the Toulmin agenda. In Hitchcock and Verheij, Arguing on the Toulmin Model: New Essays on Argument Analysis and Evaluation, pp. 49-69. Dordrecht: Springer. 